\title{
Expression and role of the inhibitor of apoptosis protein livin in chemotherapy sensitivity of ovarian carcinoma
}

\author{
XIAOMEI LIU ${ }^{1}$, AIYUAN WANG ${ }^{2}$, HONG GAO $^{1}$, ZHENGWEI YUAN $^{1}$ and YISHENG JIAO ${ }^{3}$ \\ ${ }^{1}$ Experiment Research Center, Departments of ${ }^{2}$ Ophthalmology and ${ }^{3}$ Obstetrics and Gynecology, \\ Shengjing Hospital of China Medical University, Shenyang, P.R. China
}

Received April 12, 2012; Accepted June 15, 2012

DOI: 10.3892/ijo.2012.1540

\begin{abstract}
Ovarian cancer has the highest mortality rate of all gynecological malignancies. Livin, a novel member of the inhibitor of apoptosis protein family, has been found to be expressed in various malignancies and is suggested to have poor prognostic significance. However, no data are available concerning the significance of livin in ovarian cancer. In the present study, we detected the expression of livin isoforms in human epithelial ovarian cancer (EOC) tissues using semi-quantitative RT-PCR and western blot assays. The data indicated that livin expression positive ratio was much higher in cancer tissues compared to those in benign ovarian tumors and normal ovarian specimens. To determine the role of livin in the process of ovarian cancer growth, RNA interference mediated by recombinant lentivirus vectors expressing livin shRNA was applied to induce a long-lasting downregulation of livin gene expression in SKOV3 human ovarian cancer cell line. Cell apoptosis and chemosensitivity were evaluated by MTT assay and flow cytometry, respectively, following downregulation of livin expression, and the cleavage of molecular markers of the mitochondrial apoptotic signaling pathway was investigated
\end{abstract}

Correspondence to: Dr Yisheng Jiao, Department of Obstetrics and Gynecology, Shengjing Hospital of China Medical University, Shenyang, P.R. China

E-mail: jiaoyish@163.com

Abbreviations: BIR, Baculovirus-Repeat; DDP, cis-diamminedichloroplatinum; EOC, epithelial ovarian cancer; ECL, enhanced chemiluminescence; EDTA, ethylenediaminetetraacetic acid; EGTA, ethylene glycol tetraacetic acid; HEPES, hydroxyethyl piperazine ethanesulfonic acid; IAPs, inhibitor of apoptosis proteins; IHC, immunohistochemistry; MTT, 3-(4,5-dimethylthiazol-2-yl)-2,5-diphenyltetrazolium bromide; MOI, multiplicity of infection; OD, optical density; PVDF, polyvinylidene difluoride; PMSF, phenylmethylsulfonyl fluoride; RPMI, Roswell Park Memorial Institute; RT-PCR, reverse transcription-polymerase chain reaction; SDS, sodium dodecyl sulfate; siRNA, small interference RNA; shRNA, specific short hairpin RNA

Key words: apoptosis, caspase, livin, ovarian cancer, cisplatin, chemotherapy by immunoblotting. Livin knockdown with siRNA enhanced spontaneous and drug-induced apoptosis in SKOV3 cells. The inhibition of livin resulted in profound pro-apoptotic and antiproliferative effects, and was associated with the activation of caspase signaling. In conclusion, these data suggested that livin plays an important role in inhibiting the apoptosis of ovarian cancer cells. Specific silencing of livin expression could promote cell apoptosis, enhance chemotherapy sensitivity and may be a promising target for further research in clinical chemotherapy of epitheliod ovarian cancer.

\section{Introduction}

Ovarian cancer accounts for 3\% of all cancers for women in the U.S, and is the most lethal gynecologic malignancy $(1,2)$. Ovarian cancer histologic subtypes include epithelioid (serous, endometrioid, mucinous, clear cell and undifferentiated) and non-epitheliod (3), of which the epithelial ovarian cancer (EOC) comprises about $90 \%$ of all ovarian cancers (4). Although the 5 -year survival rate for all stages has improved by combination chemotherapy with cis-diamminedichloroplatinum (DDP) (5), it is still disappointingly low, largely because of the finding that most patients present with metastatic disease and due to high intrinsic resistance towards chemotherapeutic drugs $(6,7)$, the low overall cure rates and the intolerable side effects of systemic chemotherapy asks for the development of novel and more effective pharmacological interventions.

Inhibition of apoptosis is one of the important mechanisms for the growth of many malignant tumor cells. The inhibitor of apoptosis proteins (IAPs) comprise a family of structurally related cellular factors that suppress apoptosis induced by a variety of stimuli. Up to now, eight members of IAPs family have been identified and respectively named as: NAIP (8), c-IAPI (MIHB, HIAP-2), c-IAP2 (HIAP-1, MIHC, API2) (9), XIAP (hILP, MIHA, ILP-1) (10), Survivin (11), Apollon (Bruce) (12), ILP-2 (13) and livin (ML-IAP, KIAP) (14). Livin composed of a single Baculovirus-Repeat (BIR) domain and a zinc-binding RING-domain, splicing of the gene in exon 6 yields two alternatively similar isoforms, $\alpha$ and $\beta$, except for 18 amino acids presented in the $\alpha$ variant.

Aberrant livin expression has been demonstrated in human malignancy and tumor tissue cells (15-19). In most tumors, the presence or expression level of livin correlated with in vitro 
drug resistance, advanced tumor stages, and poor outcome $(16,19)$. Antisense oligonucleotides or small interference RNA (siRNA) mediated livin knockdown have been shown to reduce tumor cell proliferative potential and/or induce sensitization toward proapoptotic simuli in renal cell carcinoma cells, lung cancer cells or neuroblastoma cells (20-23). Together, these studies suggest that livin may be essential for survival of some cancer cells.

In our previous work (24), the expression of livin was detected by immunohistochemistry (IHC) in $72 \%$ of investigated patients with EOC. Because evaluation of staining intensity by IHC is subject to observer variability, we precede this follow-up study to assess livin expression in EOC tumor tissues by RT-PCR and western blot, as the latter two methods are more quantifiable and reproducible methods. In addition, we inhibited endogenous livin expression in EOC cell lines by specific short hairpin RNA (shRNA). We show that targeted silencing of the livin gene efficiently sensitized EOC cells towards chemotherapeutic stimulus. These studies highlight targeted inhibition of livin as a novel therapeutic strategy in ovarian cancer.

\section{Materials and methods}

Tissue samples. Frozen tumor specimens were obtained from 50 patients with EOC. The median patient age was 56 years (range 38-82). The histological type and histological grade were as follows: subtype (serous, 22 cases; mucinous, 12 cases; endometrioid, 8 cases; clear cell, 8 cases), and grade (G1, 15 cases; G2, 10 cases; G3, 35 cases). Clinical stages, determined according to the FIGO system (International Federation of Gynecologists and Obstetricians) were stage I-II in 12 patients, stage III-IV in 38 patients. Twenty samples of normal ovarian tissues were obtained from patients undergoing ovarian biopsy or ovariotomy (patients suffering from uterine fibroids, dysfunctional uterine bleeding or uterine prolapse underwent hysterectomy meanwhile, pathologically precluded abnormality in ovarian tissues), which aged ranging from 42 to 68 years (median age 49). Twenty samples of benign ovary tumor were obtained from patients (15 cases of serous cystadenoma and 5 cases of mucinous cystadenoma) aged ranging from 24 to 58 years (median age 43). These samples were collected from patients admitted to the Shengjing Hospital of China Medical University (Shenyang, China). None of the patients had received chemotherapy, radiotherapy or immunotherapy. This work was approved by the ethical committee of the China Medical University. Informed consent was obtained from each patient.

RNA extraction and semi-quantitative RT-PCR. Total RNAs were extracted from tissue samples using TRIzol reagent (Invitrogen, Carlsbad, CA, USA) according to the manufacturer's instructions. The amount of RNA was quantified in duplicate using UV absorbance at $260 \mathrm{~nm}$. Equal amounts of total RNA was reverse-transcribed into cDNA using the Takara RNA PCR kit (DRR037, Takara, Dalian, China) in a final volume of $20 \mu 1$ following the manufacturer's protocol. To minimize variation in the reverse transcription reaction, all RNA samples from a single experimental setup were reverse transcribed simultaneously. The PCR primers were as follows: for livin (GenBank: AF311388) specific primers discriminating between the $\alpha$ - and the $\beta$ variants were: sense, 5'-AGTTCCTGCTCCGGTCAAA-3'; antisense, 5'-GCACGGCACAAAGACGAT-3', which yields two products of $347 \mathrm{bp}$ and $293 \mathrm{bp}$, respectively; and for $\beta$-actin (GenBank: NM_001101) (internal control), sense 5'-GATTGGCTCAGGACATTTCTG-3' antisense 5'-GATTGCTCAGGACATTTCTG-3' (751 bp). The amplification conditions were as follows: denaturation at $94^{\circ} \mathrm{C}$ for $5 \mathrm{~min} ; 32$ cycles of $94^{\circ} \mathrm{C}$ for $40 \mathrm{sec}, 55^{\circ} \mathrm{C}$ (for livin) and $52^{\circ} \mathrm{C}$ (for $\beta$-actin) for $1 \mathrm{~min}, 72^{\circ} \mathrm{C}$ for $1 \mathrm{~min}$; and a final $5 \mathrm{~min}$ extension at $72^{\circ} \mathrm{C}$. The PCR products were separated on $2 \%$ agarose gels, and the bands were visualized by ethidium bromide and photographed under UV light.

Immunoblotting assay. Frozen tissues were washed with icecold PBS and homogenized in lysis buffer $(50 \mathrm{mM}$ Tris- $\mathrm{HCl}$ $\mathrm{pH}$ 7.5, $150 \mathrm{mM} \mathrm{NaCl}, 5 \mathrm{mM}$ EDTA, $5 \mathrm{mM}$ EGTA, $1 \mathrm{mM}$ PMSF, 0.1\% Nonidet P-40, 0.1\% Triton X-100, 50 mM NaF, $0.5 \mathrm{mM} \mathrm{Na}_{3} \mathrm{VO}_{4}$ ). Lysates were centrifuged at $12,000 \mathrm{x} \mathrm{g}$ for $20 \mathrm{~min}$ at $4^{\circ} \mathrm{C}$ and supernatants collected. Protein concentrations were determined using Bradford protein assay (Bio-Rad Laboratories, Hercules, CA, USA). Equal amounts of proteins were separated on 12\% SDS-polyacrylamide gel electrophoresis and transfered onto a polyvinylidene difluoride (PVDF) membrane (Millipore, Billerica, MA, USA). The membrane was then blocked with 5\% nonfat milk and immunoprobed with rabbit polyclonal anti-livin antibody (IMG-347, Imgenex, San Diego, CA, USA), followed by exposed to horseradish peroxidase-conjugated secondary antibody and visualized using ECL plus reagent (GE Healthcare, Piscataway, NJ, USA). Quantity One software (Bio-Rad) was applied for analysis of the optical density of the protein bands. The relative expression quantity of livin protein was illustrated as the percentage of the optical density (OD) of livin protein, adjusted with the corresponding $\beta$-actin OD.

Construction of livin shRNA vectors. Four non-overlapping segments which are located at 786-804, 647-665, 609-627 and 519-537 position in livin cDNA (NM_022161.2) were selected as candidate targets using Target Finder and Design Tool of Ambion (http://www.ambion.com/techlib/misc/siRNA_tools. html). The dsDNA sequences simultaneously aimed at both of the two variants. Another shRNA of nonspecific sequence was used as a control (Table I). BLAST search of the human genome database was carried out and found no homology with other human genes. Then, these shRNAs were subcloned into lentiviral vector pGCL-GFP (GeneChem, Shanghai, China) plasmid between the HpaI and XhoI enzyme sites and the recombinants generated were named Psi-1, Psi-2, Psi-3, Psi-4 and Psi-NC. The inserts in those recombinants were confirmed by DNA sequencing (data not presented).

Cell culture and transfection. Ovarian cancer cell lines SKOV3 cells (purchased from Cancer Institute, Chinese Academy of Medical Sciences) were cultured in RPMI-1640 medium with $10 \%$ fetal bovine serum (FBS) and seeded in 6-well plates and allowed overnight growth to reach $70-80 \%$ confluence. Cells were then transfected with each of the siRNA recombinants using Lipofectamine ${ }^{\mathrm{TM}} 2000$ 
Table I. Candidate livin shRNAs and the target sequences.

\begin{tabular}{llcc}
\hline & \multicolumn{1}{c}{ Target sequence $\left(5^{\prime} \rightarrow 3^{\prime}\right)$} & Position & GC percent $(\%)$ \\
\hline Psi-1 & CAGGCCATCAGGACAAGGT & $786-804$ & 57.14 \\
Psi-2 & GGAAGAGACTTTGTCCACA & $647-665$ & 47.62 \\
Psi-3 & GGAGAGAGGTCCAGTCTGA & $609-627$ & 52.38 \\
Psi-4 & AGTGGTTCCCCAGCTGTCA & $519-537$ & 57.14 \\
Psi-NC & TTCTCCGAACGTGTCACGT & - & 52.63 \\
\hline
\end{tabular}

reagent (Invitrogen). For confirmation of downregulation of livin gene, after $72 \mathrm{~h}$, cells were harvested and analyzed for reduction of livin expression by real-time RT-PCR and immunoblotting. The lentiviral vector giving maximal knockdown was selected and packaged by the $293 \mathrm{~T}$ packaging cell and the vector particles were concentrated. During the transfection protocol, the most suitable MOI (multiplicity of infection) of lentivirus is MOI 20. Controls consisted of either Lipofectamine-treated (untreated) or control siRNAtreated cells (MOI 20) alone.

Real-time RT-PCR. Total RNA was extracted from treated cells and reverse transcripted into cDNA as mentioned above. The real-time PCR primers were as follows: Livin: sense, 5'-GCGTCTGGCCTCCTTCTATG-3' antisense, 5'-AAGCACCTCACCTTGTCCTG-3' (108 bp), which did not discriminate between the two livin isoforms. $\beta$-actin: sense, 5'-GTGGACATCCGCAAAGAC-3'; antisense 5'-AAAGGGTGTAACGCAACTA-3' (302 bp). Untreated group values were used as calibrator. The relative level was calculated using the $2^{-\Delta \Delta \mathrm{Ct}}$ method after normalization with $\beta$-actin as a housekeeping gene (25).

Cell lysis and immunoblotting. Treated cells were harvested and protein was extracted, separated and transferred onto PVDF membrane as described earlier. Filters were probed with either rabbit polyclonal anti-active caspase 9 antibody (ab25759, Abcam, Cambridge, MA, USA), anti-active caspase 7 antibody (ab2323, Abcam) or anti-active caspase 3 antibody (ab2302, Abcam) followed by secondary antibody and developed by ECL staining.

Cell proliferation assay. Cell proliferation was investigated by colorimetric assay using 3-(4,5-dimethylthiazol-2-yl)-2, 5-diphenyltetrazolium bromide (MTT). In brief, SKOV3 cells were plated in a 96 -well flat-bottomed plate at $5 \times 10^{3}$ cells $/$ well in triplicate and cultured in medium for $24 \mathrm{~h}$. Then the cells were treated with lentiviral livin shRNA or control siRNA for 24, 48, 72 and $96 \mathrm{~h}$. On each experimental point, $20 \mu \mathrm{l}$ MTT $(5 \mathrm{mg} / \mathrm{ml}$ in PBS) was added to each well, and the cells were incubated at $37^{\circ} \mathrm{C}$ for additional $4 \mathrm{~h}$. Then the reaction was stopped by lysing the cells with $150 \mu \mathrm{l}$ DMSO for $5 \mathrm{~min}$. The absorbance of each well were measured at $570 \mathrm{~nm}$ using a microtitre plate reader (Labsystems MK3, Finland). The data were normalized to the untreated group. All experimental points were set up in three replicate wells and independently performed three times.
Apoptosis assay. Cell apoptosis assay were performed by flow cytometry after $72 \mathrm{~h}$ since the cells were transfected with siRNAs. Briefly, cells were seeded in 6-well plates in triplicate at $1 \times 10^{5}$ cells/well and transfected as described earlier. At $72 \mathrm{~h}$ post-transfection, the cells were harvested, washed twice with cold PBS, suspended in 1X binding buffer [10 mM HEPES (pH 7.4), $150 \mathrm{mM} \mathrm{NaCl}, 2.5 \mathrm{mM} \mathrm{CaCl}_{2}, 1 \mathrm{mM} \mathrm{MgCl}_{2}, 4 \%$ BSA] at a concentration of $1 \times 10^{6}$ cells $/ \mathrm{ml}$. Cells were incubated in the dark for $15 \mathrm{~min}$ at room temperature with $5 \mu \mathrm{l}$ Annexin V-FITC (BD Biosciences Pharmingen, Allschwill, Switzerland). Before analysis, $2.5 \mu \mathrm{l}$ of 7-AAD was added to the samples in a final volume of $200 \mu \mathrm{l}$. A total of 10,000 cells were accumulated with a BD FACSCaliburH apparatus and data were analyzed using the CellQuest software. Apoptotic cells were determined by Annexin V-positive and 7-AAD negative cells.

Chemosensitivity assay. Cells were treated with lentiviral siRNA for $48 \mathrm{~h}$, and then with seven concentration gradient of DPP in PBS $(100,50,25,12.5,6.25,3.13,1.56 \mathrm{mg} / \mathrm{l})$ for $24 \mathrm{~h}$; the effects on cell growth were examined by MTT assay as described earlier, the growth inhibition was calculated according to the following formula: Inhibitory ratio $(\%)=$ [1- (OD of the lentiviral siRNA/OD of the untreated) x100\%]. After treated with siRNA plus DPP $(5 \mathrm{mg} / \mathrm{l})$, flow cytometry was performed to detect cells apoptosis, and active caspase 9,7, 3 were determined as indicated above.

Statistical analysis. All experiments were repeated in triplicate and data were expressed as mean \pm standard deviation of the mean (SD). Statistical significance was assessed by one-way ANOVA followed by Bonferroni multiple comparison posttests. Statistical analyzes were performed using SPSS 13.0 package (SPSS, Chicago, IL, USA). p $<0.05$ was considered significant.

\section{Results}

Livin $m R N A$ and protein expression in EOC. Livin mRNA was detected in 32 of 50 (64\%) EOC tumor specimens, 3 of $20(15 \%)$ benign tumors, 2 of $20(10 \%)$ normal ovary tissues, respectively $\left(\chi^{2}=24.448, \mathrm{P}<0.01\right)$ (Fig. $\left.1 \mathrm{~A}\right)$. The expression levels of total livin differed greatly among the 32 positive tumor samples; with no obvious difference between two isoforms (data not shown) (Fig. 1B). The mean livin mRNA value among the 32 positive cases was set as 1.0. High expression levels (defined as values greater than the mean positive tumor 
A
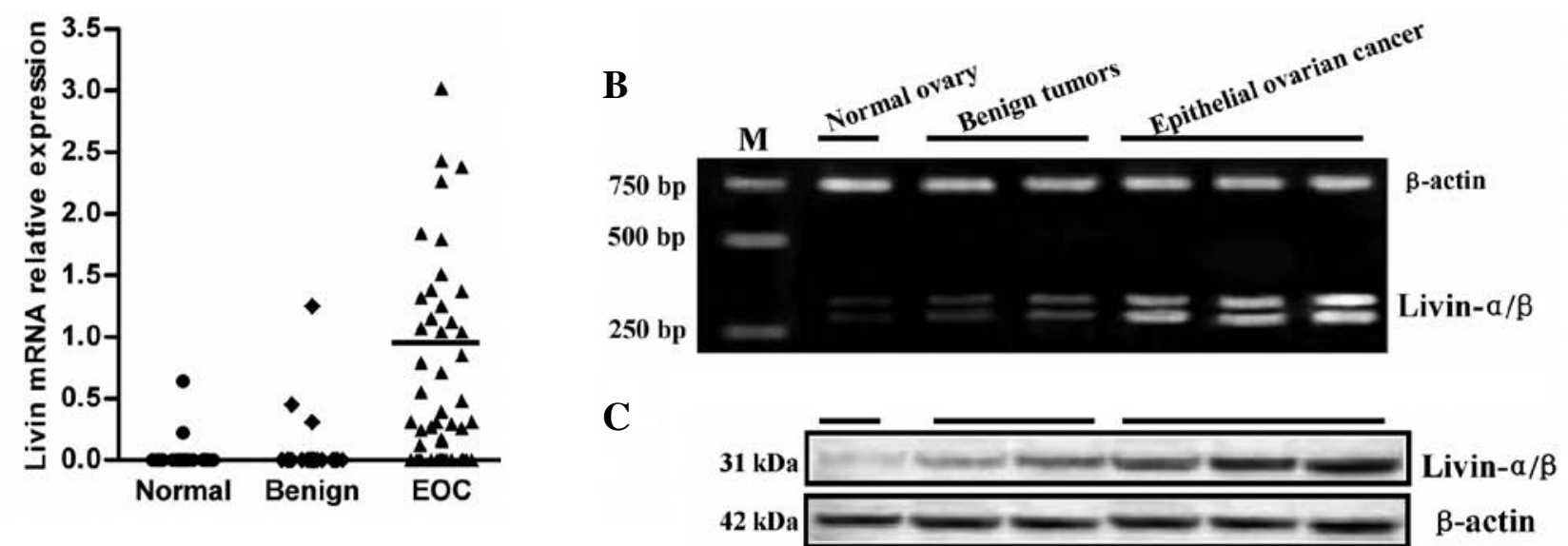

Figure 1. Livin mRNA and protein expression levels in tissue specimens. (A) Semi-quantative RT-PCR values for livin mRNA level in 50 EOC, 20 benign ovarian tumors and 20 normal ovarian tissues. Bar represents the mean value (1.0) for livin expression in positive primary tumors. (B) Representative expression of livin mRNA detected by RT-PCR for positive specimens. (C) Representative livin protein expression and $\beta$-actin (internal control) by western blot analysis for corresponding specimens. The data were normalized to the internal control $\beta$-actin, and represent the mean values \pm SD.

A
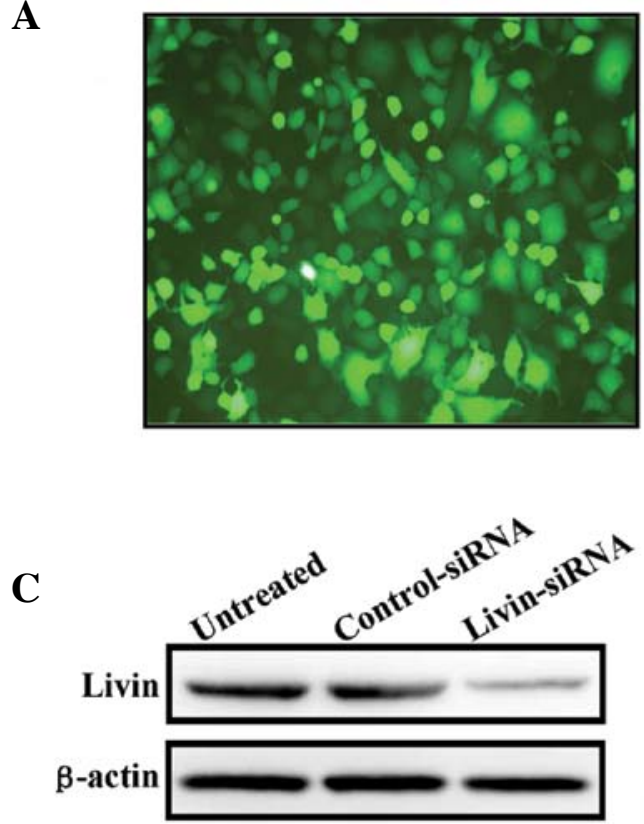

B
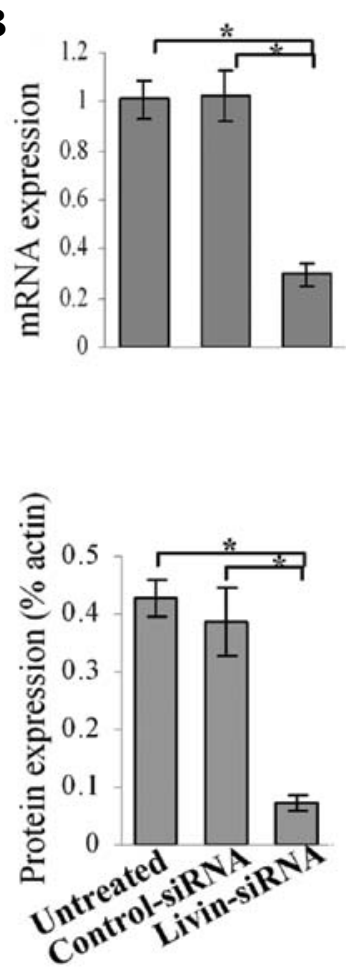

Figure 2. The livin shRNA lentivirus silenced livin expression in the SKOV3 cells. Effective livin targets that simultaneously aimed at both of the two livin isomers in the livin gene were designed, synthesized, and packaged by lentiviruses. (A) SKOV3 cells were successfully infected with livin Psi-4 shRNA lentivirus at MOI 20 for $72 \mathrm{~h}$; most of the survived cells were GFP positive (original magnification, $\mathrm{x} 400$ ). (B) The livin mRNA expression decreased significantly in $72 \mathrm{~h}$ post-infection with livin Psi-4 shRNA detected by real-time RT-PCR. The data were normalized to the untreated control. (C) Immunoblotting evaluations showed that livin protein expression was significantly reduced at $72 \mathrm{~h}$ post-infection. The data were normalized to the internal control $\beta$-actin, and represent the mean values $\pm \mathrm{SD}$. ${ }^{*} \mathrm{p}<0.05$ vs. untreated.

level) were observed in 16 tumors. These included 4/12 (33\%) patients with advanced stage (III and IV) disease, 12/38 (32\%) patients with localized stage (I and II) disease. No obvious link was observed between the expression levels with tumor stage or tumor grade for the limited numbers of tissue samples investigated here. Generally, comparable changes in livin protein concentrations were also observed. Thirty-two of the
50 (64\%) tumor specimens assessed by immunoblotting were positive for livin protein; all of these specimens were also positive by RT-PCR (Fig. 1C). Conversely, all the specimens negative by RT-PCR were also negative for livin protein.

Silencing of livin gene expression by RNAi in SKOV-3 cells. SKOV3 cells were transfected with different shRNA 
A

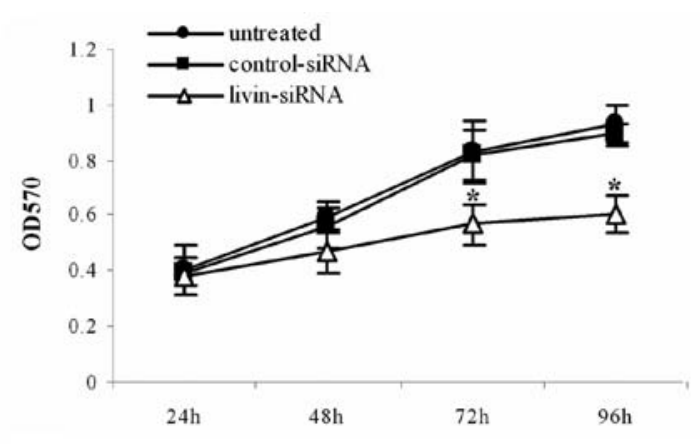

B

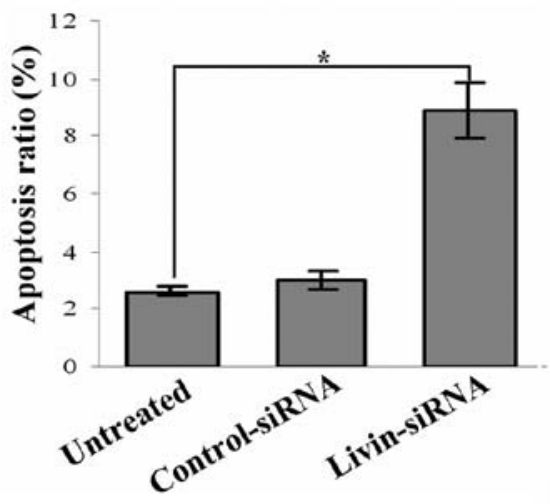

C

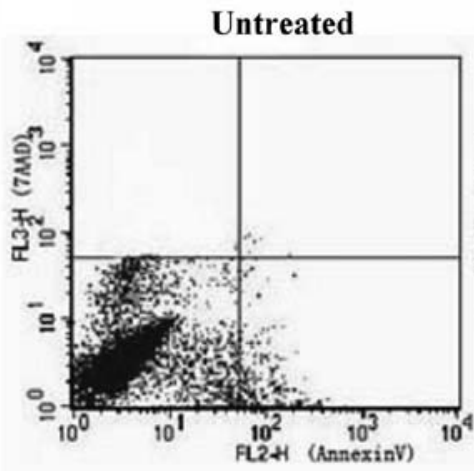

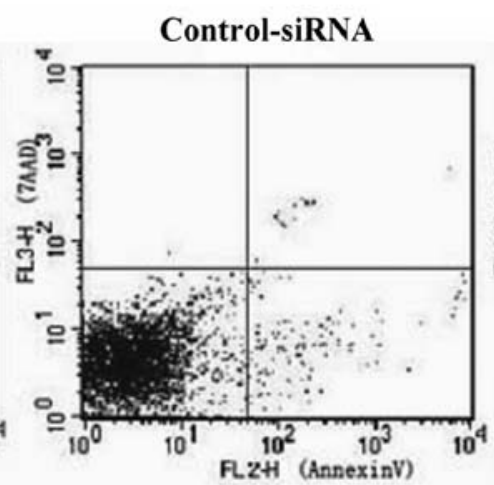

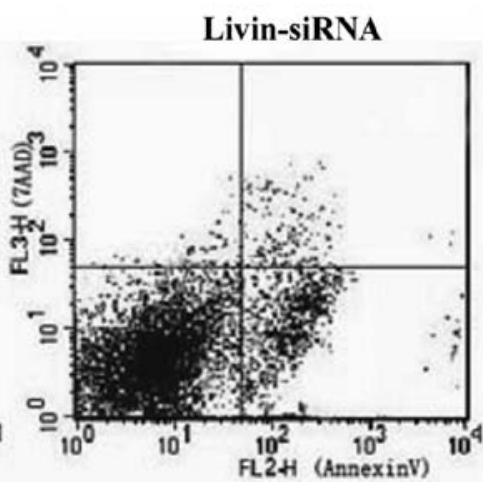

Figure 3. Silencing of livin gene expression by RNAi induced cell apoptosis in SKOV3 cells. (A) MTT assay showed that the cell proliferation of SKOV3 cells infected with livin shRNA was significantly decreased compared with the controls. (B and C) Flow cytometry revealed that the percentage of apoptotic cells (determined by Annexin V-positive and 7-AAD-negative cells) were increased in the livin-siRNA infected cells, compared to the controls. * ${ }^{*}<0.05$ vs. untreated.

constructs to screened effective targets of livin and obtained the optimum concentration for lentivirus transfection. The knockdown efficiency of four candidate shRNA was evaluated using western blotting. The results disclosed that the best knockdown effect was with Psi-4 siRNA at MOI 20 (data not shown). At $72 \mathrm{~h}$ post-transfection with Psi-4 siRNA more than $90 \%$ of the survived cells were GFP-positive (Fig. 2A). Realtime RT-PCR analyses performed at $72 \mathrm{~h}$ post-transfection showed that livin mRNA levels were significantly reduced by $70 \%$ when compared with control transfections (Fig. 2B). To correlate the decrease in livin mRNA expression with livin protein levels, immunoblotting analysis was performed at $72 \mathrm{~h}$ after siRNA treatment. The protein levels were reduced, thereby confirming efficient knockdown (Fig. 2C).

Livin siRNA induces spontaneous apoptosis in SKOV-3 cells. We first tested the effect of livin siRNA on SKOV-3 cell proliferation by a colorimetric assay using MTT, and the inhibition rate was calculated with the method above. The results showed that silencing of livin gene has substantially effect on SKOV3 cells proliferation compared with control groups (both $\mathrm{P}<0.05$ ) (Fig. 3A).

The cell apoptosis was measured by flow cytometry at $72 \mathrm{~h}$ after transfection; apoptosis cells were determined by Annexin V-positive and 7-AAD-negative cells (Fig. 3B and C). The results demonstrated that the apoptosis ratio of livin siRNA cells obviously increased compared with control groups (both $\mathrm{P}<0.05)$.

We further investigated the cleavage of several molecular markers of mitochondrial apoptotic signaling pathway, including caspase 9, caspase 3 , and caspase 7 by immunoblotting after SKOV-3 cells were stably transfected with livin siRNA for $72 \mathrm{~h}$. As shown in Fig. 4, the results showed that in the livin siRNA cells, cleavage of caspase 9, caspase 3 and caspase 7 was remarkably increased, compared with control groups (all $\mathrm{P}<0.05$ ).

Inhibition of livin gene sensitizes SKOV3 cells towards DPP stimulus. Livin siRNA- or control siRNA-transfected cells were treated separately with DPP for various concentrations and the growth inhibition curves are shown in Fig. 5A. The results showed that the silencing of livin expression resulting in strikingly higher cell growth inhibition at different drug concentrations. The IC50 for untreated and control-siRNA were 13.96 and 14.58 , but the IC50 for livin-siRNA dropped to $6.67(\mathrm{P}<0.05)$.

Cell apoptosis were determined by Annexin-V/7AAD assay (Fig. 5B). In SKOV3 cells, treatment with livin siRNA plus DPP $(5 \mathrm{mg} / \mathrm{l})$ resulted in a significantly higher apoptosis proportion $(29.89 \pm 3.29)$ compared to control siRNA plus DPP $(7.62 \pm 0.95)$ or DPP alone $(6.66 \pm 0.69)$ (both $\mathrm{P}<0.05)$. These results suggest that livin inhibition by lentiviral shRNA 

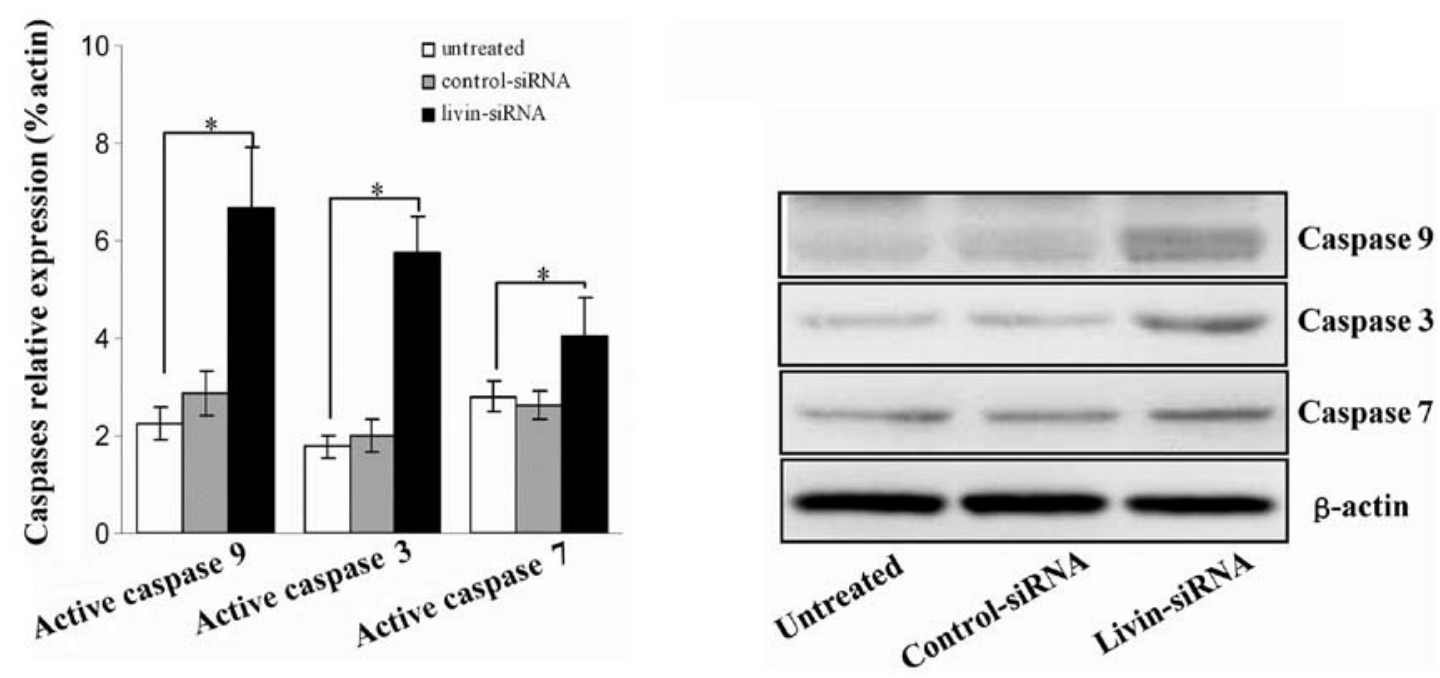

Figure 4. Impact of livin lentivirus vectors on cleavage of caspase 9,7 and 3 expression levels. Western blot analysis showed cleaved caspase 9,7 and 3 protein levels were remarkably increased, after livin shRNA lentivirus infection of SKOV3 cells. The data were normalized to the internal control $\beta$-actin, and represent the mean values \pm SD. ${ }^{*} p<0.05$ vs. untreated.
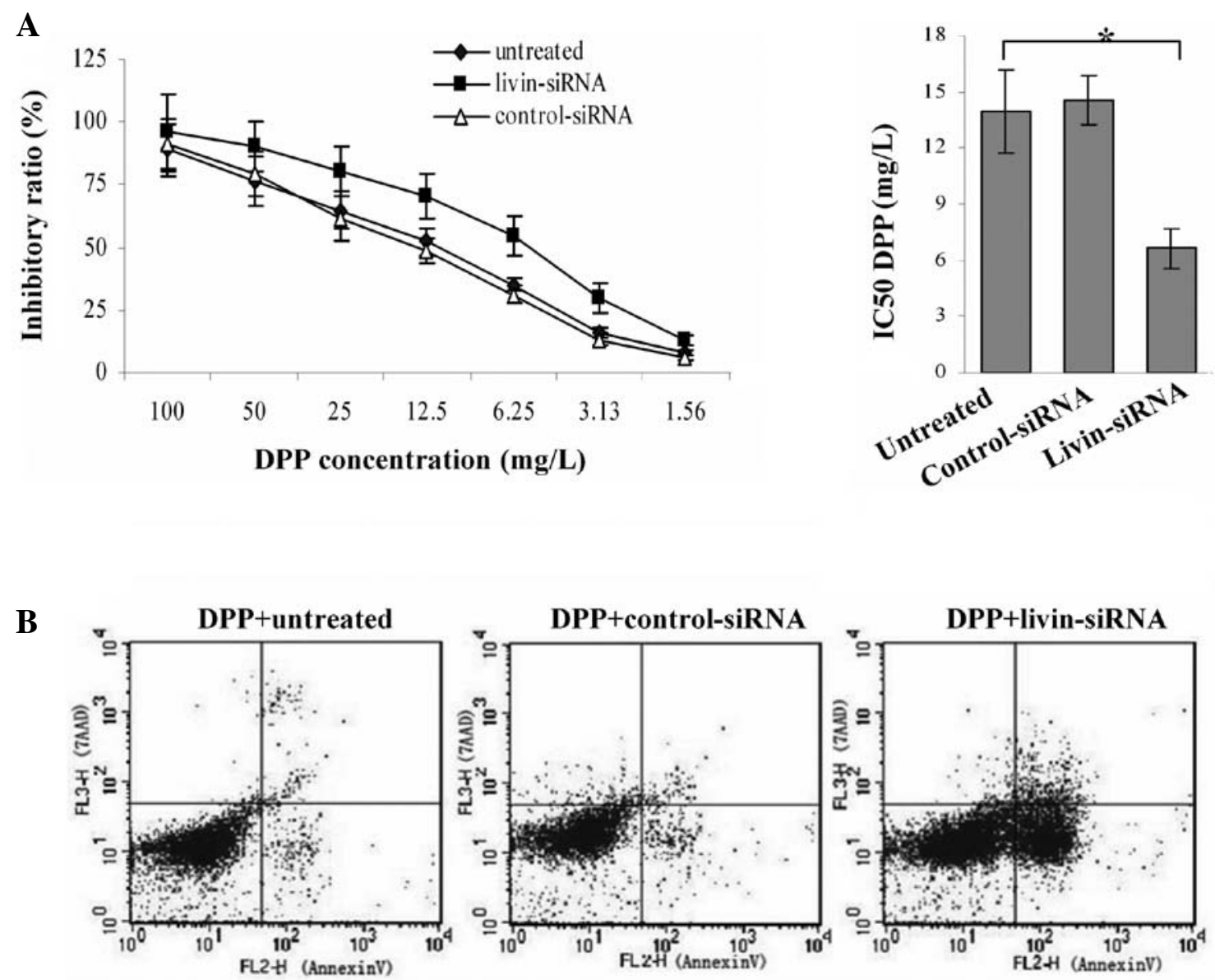

Figure 5. Inhibition of livin expression sensitizes SKOV3 cells toward DPP stimulus. (A) Inhibition curves of DPP at seven different test drug concentrations. SKOV3 cell knockdown of livin showed higher sensitivity to DPP as evidenced by lower IC50. (B) Flow cytometry revealed that DPP-induced apoptotic ratio in SKOV3 cells was notably increased after silencing of the livin. " $\mathrm{p}<0.05$ vs. untreated.

resulted in remarkable enhancement in chemosensitivity of DPP for SKOV3 cells.

Before livin inhibition, treatment with DPP alone resulted in activation of apoptosis signaling pathway with increased cleavage of caspase 9, caspase 3 and caspase 7 in SKOV3 cells. Targeted inhibition of livin gene existed synergistic effect on induction of apoptosis in SKOV3 cells, as evidenced by a dramatical enhancement of caspase 9,7 and 3 cleavages compared with control siRNA-treated cells after treatment with DPP (Fig. 6). 

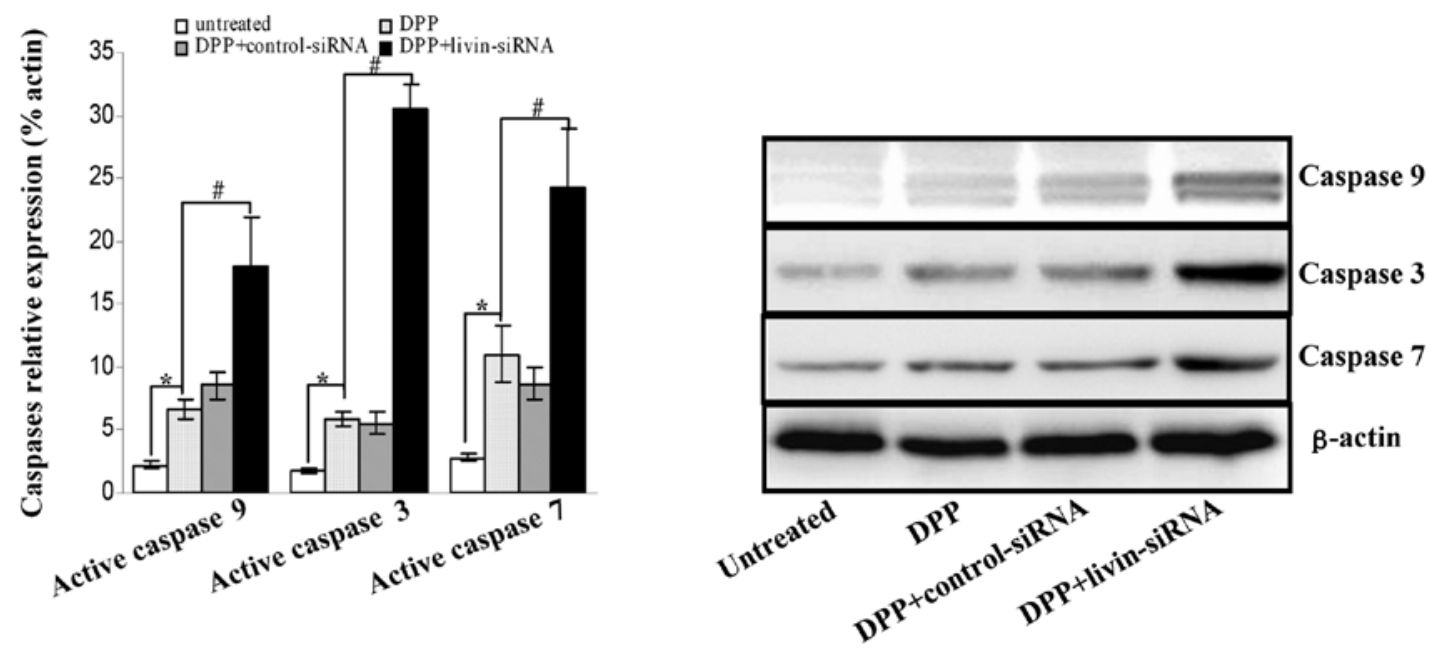

Figure 6. DPP-induced apoptosis in SKOV3 cells before and after silencing of the livin. DPP activated caspase 9, 7 and 3 protein levels were detected by immunoblotting in SKOV3 cells with or without silencing the livin. Inhibition of livin exhibited synergistic effect on induction of apoptosis, with remarkable enhancement of caspase 9, 7 and 3 cleavages compared with the controls. The data were normalized to the internal control $\beta$-actin, and represent the mean values \pm SD. ${ }^{~} \mathrm{p}<0.05$ vs. untreated, ${ }^{\#} \mathrm{p}<0.05$ vs. DPP.

\section{Discussion}

Ovarian cancer has the highest mortality rate of all gynecologic malignancies. Despite considerable progress in therapies, including surgery, radiation, especially chemotherapy, the overall survival for patients with ovarian cancer has not improved substantially. High intrinsic resistance of ovarian cancer cells to chemotherapeutic drugs may contribute to the failure of the treatment. Among the reasons of chemotherapy resistance, apoptosis deficiency is considered to be a major cause, since many chemotherapy agents act through the induction of apoptosis (26). So it is important to identify the molecular determinants that mediate the apoptotic resistance of ovarian cancer cells for the development of novel and more effective therapy strategies.

Livin, a new member of IAPs family, has been shown to be expressed in transformed cells and multiple malignant tumors, such as carcinomas of the prostate, renal, gastric, bladder, lung and breast, but not detectable in most normal differentiated tissues with the exception of the placenta, normal testes and spinal cord $(15,27-29)$. The antiapoptotic activity of livin is mediated via inhibition of the mitochondrial apoptotic signaling pathway molecules caspase 3,7 , and 9 , as well as by its E3 ubiquitin-ligase-like activity that promotes degradation of Smac/DIABLO, a critical endogenous regulator of all IAPs $(30,31)$. Pilot studies of molecular profiling and retrospective analysis showed that livin has a strong correlation with shorter disease-free or overall survival in most cases, and identified livin expression as a candidate independent prognostic indicator of poor outcome in patients with some tumor types $(15,18,32)$. The above studies, along with the confirmed antiapoptotic activity of livin, have raised considerable interest in developing strategies for the therapeutic inhibition of livin in cancers. It has been shown that downregulation of livin gene expression by RNA interference or antisense oligonucleotides reduces the growth of livin-expressing cancer cells and can resensitise tumor cells towards proapoptotic anticancer agents (33-35).
In our initial studies, we evaluated the expression of livin in individual primary ovarian cancer frozen tissues (Fig. 1). The presence of both livin isoforms was demonstrated by RT-PCR and western blot in $64 \%$ of EOC tumors studied, on the contrary only $10-15 \%$ in benign and normal ovary tissues. This finding confirms and extends our previous work using IHC. Contrary to our results, another study did not detect livin expression in ovarian carcinoma, possibly due to the limited number and complexity of specimens (only 12 solid tumors including ovarian carcinoma, tubal carcinoma, primary peritoneal carcinoma, and 16 peritoneal and pleural effusions) (36). Although the number of EOC specimens under investigation is limited, the positive percentage for livin expression (64\%) is similar to the data from previously studies on other cancer types, such as melanoma (70.6\%) (37) and lung cancer (76.3\%) (27). Notably, previous studies showed that livin expression or presence is significantly correlated with tumor stage, increasing with tumor progression. We did not find correlation between livin expression and tumor stage or histological grade, possibly because of the limited specimens, but high presence indicated that it is closely related to EOC formation and pathological progression. Further studies involving large number of samples of EOC cases and long-term follow-up are required to investigate the relationship of livin with EOC tumor stage and grade.

We further studied the livin function by gene-silencing studies, targeted inhibition of endogenous livin expression in SKOV3 cells resulted in downregulation of livin and increased cell apoptosis, which was caused by activation of mitochondrial apoptotic signaling pathway as evidenced by increased activation of caspase 9, caspase 3, and caspase 7 . Enhanced sensitivity of siRNA-transfected tumor cells to DPP was also observed, as suggested by increased DPP-induced apoptosis by greater than $350 \%$. Our results are in line with data of previous studies for HeLa cervical carcinoma cells (38), non-small cell lung cancer (39), and renal cell carcinoma (34). All these studies suggested that the inhibition of livin sensitize livin-expressing cancer cells to chemotherapy stimuli. 
In summary, our data suggest that the livin is expressed in EOC and contributes to the apoptotic resistance of EOC cells, a combination of downregulation of livin and DPP can significantly enhance the apoptosis induced by DPP. Thus, using combined treatment with DPP and livin inhibition may provide an effective strategy for ovary cancer therapy. However, to realize the therapeutic potential of RNA drugs, efficient, tissue-specific and nonimmunogenic delivery technologies must be developed. Recently, ultrasound-mediated and exosome-endogenous nano-vesicles mediated siRNA delivery was reported to greatly promote the specificity and efficiency of transfection $(40,41)$. Further studies are necessary to determine whether these techniques can provide a more effective route for siRNA-mediated gene therapy.

\section{Acknowledgements}

We thank Yaoqiong Cao (GeneChem Co. Ltd, Shanghai, China) for technical assistance. This work was supported in part by grant from the National Natural Science Foundation of China (grant no: 81100432).

\section{References}

1. Jemal A, Siegel R, Ward E, Murray T, Xu J and Thun MJ: Cancer statistics, 2007. CA Cancer J Clin 57: 43-66, 2007.

2. Campos SM and Ghosh S: A current review of targeted therapeutics for ovarian cancer. J Oncol: 149362, 2010.

3. Siwak DR, Carey M, Hennessy BT, et al: Targeting the epidermal growth factor receptor in epithelial ovarian cancer: current knowledge and future challenges. J Oncol: 568938, 2010.

4. Feeley KM and Wells M: Precursor lesions of ovarian epithelial malignancy. Histopathology 38: 87-95, 2001.

5. Kim A, Ueda Y, Naka T and Enomoto T: Therapeutic strategies in epithelial ovarian cancer. J Exp Clin Cancer Res 31: 14, 2012

6. Trimble EL, Wright J and Christian MC: Treatment of platinum-resistant ovarian cancer. Expert Opin Pharmacother 2: 1299-1306, 2001.

7. Agarwal R and Kaye SB: Ovarian cancer: strategies for overcoming resistance to chemotherapy. Nat Rev Cancer 3: 502-516, 2003.

8. Roy N, Mahadevan MS, McLean M, et al: The gene for neuronal apoptosis inhibitory protein is partially deleted in individuals with spinal muscular atrophy. Cell 80: 167-178, 1995.

9. Rothe M, Pan MG, Henzel WJ, Ayres TM and Goeddel DV: The TNFR2-TRAF signaling complex contains two novel proteins related to baculoviral inhibitor of apoptosis proteins. Cell 83 1243-1252, 1995.

10. Liston P, Roy N, Tamai K, et al: Suppression of apoptosis in mammalian cells by NAIP and a related family of IAP genes. Nature 379: 349-353, 1996.

11. Ambrosini G, Adida C and Altieri DC: A novel anti-apoptosis gene, survivin, expressed in cancer and lymphoma. Nat Med 3: 917-921, 1997.

12. Chen Z, Naito M, Hori S, Mashima T, Yamori T and Tsuruo T: A human IAP-family gene, apollon, expressed in human brain cancer cells. Biochem Biophys Res Commun 264: 847-854, 1999.

13. Richter BW, Mir SS, Eiben LJ, et al: Molecular cloning of ILP-2, a novel member of the inhibitor of apoptosis protein family. Mol Cell Biol 21: 4292-4301, 2001.

14. Salvesen GS and Duckett CS: IAP proteins: blocking the road to death's door. Nat Rev Mol Cell Biol 3: 401-410, 2002.

15. Kempkensteffen C, Hinz S, Christoph F, et al: Expression of the apoptosis inhibitor livin in renal cell carcinomas: correlations with pathology and outcome. Tumour Biol 28: 132-138, 2007.

16. Ashhab Y, Alian A, Polliack A, Panet A and Ben Yehuda D: Two splicing variants of a new inhibitor of apoptosis gene with different biological properties and tissue distribution pattern. FEBS Lett 495: 56-60, 2001.

17. Vucic D, Stennicke HR, Pisabarro MT, Salvesen GS and Dixit VM: ML-IAP, a novel inhibitor of apoptosis that is preferentially expressed in human melanomas. Curr Biol 10: 1359-1366, 2000 .
18. Nedelcu T, Kubista B, Koller A, et al: Livin and Bcl-2 expression in high-grade osteosarcoma. J Cancer Res Clin Oncol 134: 237-244, 2008

19. Kim DK, Alvarado CS, Abramowsky CR, et al: Expression of inhibitor-of-apoptosis protein (IAP) livin by neuroblastoma cells: correlation with prognostic factors and outcome. Pediatr Dev Pathol 8: 621-629, 2005.

20. Ye L, Song X, Li S, et al: Livin- $\alpha$ promotes cell proliferation by regulating G1-S cell cycle transition in prostate cancer. Prostate 71: 42-51, 2011.

21. Dasgupta A, Alvarado CS, Xu Z and Findley HW: Expression and functional role of inhibitor-of-apoptosis protein livin (BIRC7) in neuroblastoma. Biochem Biophys Res Commun 400: 53-59, 2010.

22. Wang TS, Ding QQ, Guo RH, et al: Expression of livin in gastric cancer and induction of apoptosis in SGC-7901 cells by shRNAmediated silencing of livin gene. Biomed Pharmacother 64: 333-338, 2010.

23. Mousavi-Shafaei P, Ziaee AA, Azizi E and ZangemeisterWittke U: Antisense-mediated melanoma inhibitor of apoptosis protein downregulation sensitizes G361 melanoma cells to cisplatin. Anticancer Drugs 17: 1031-1039, 2006.

24. Jiao YS, Wang YL, Zhang SL, Liu XM and Hao FJ: The expression and significance of Livin and Smac in epithelial ovarian carcinoma tissues. Modern Oncol 17: 296-299, 2009.

25. Livak KJ and Schmittgen TD: Analysis of relative gene expression data using real-time quantitative PCR and the 2(-Delta Delta C(T)) method. Methods 25: 402-408, 2001.

26. Igney FH and Krammer PH: Death and anti-death: tumour resistance to apoptosis. Nat Rev Cancer 2: 277-288, 2002.

27. Tanabe H, Yagihashi A, Tsuji N, Shijubo Y, Abe S and Watanabe N: Expression of survivin mRNA and livin mRNA in non-small-cell lung cancer. Lung Cancer 46: 299-304, 2004.

28. Ka $\mathrm{H}$ and Hunt JS: Temporal and spatial patterns of expression of inhibitors of apoptosis in human placentas. Am J Pathol 163: 413-422, 2003.

29. Yagihashi A, Asanuma K, Tsuji N, et al: Detection of anti-livin antibody in gastrointestinal cancer patients. Clin Chem 49: 1206-1208, 2003.

30. Chang H and Schimmer AD: Livin/melanoma inhibitor of apoptosis protein as a potential therapeutic target for the treatment of malignancy. Mol Cancer Ther 6: 24-30, 2007.

31. Ma L, Huang Y, Song Z, et al: Livin promotes Smac/DIABLO degradation by ubiquitin-proteasome pathway. Cell Death Differ 13: 2079-2088, 2006.

32. Wagener N, Crnkovic-Mertens I, Vetter C, et al: Expression of inhibitor of apoptosis protein Livin in renal cell carcinoma and non-tumorous adult kidney. Br J Cancer 97: 1271-1276, 2007.

33. Alvarez-Salas LM and DiPaolo JA: Molecular approaches to cervical cancer therapy. Curr Drug Discov Technol 4: 208-219, 2007.

34. Crnkovic-Mertens I, Wagener N, Semzow J, et al: Targeted inhibition of Livin resensitizes renal cancer cells towards apoptosis. Cell Mol Life Sci 64: 1137-1144, 2007.

35. Pirollo KF and Chang EH: Targeted delivery of small interfering RNA: approaching effective cancer therapies. Cancer Res 68: 1247-1250, 2008.

36. Kleinberg L, Florenes VA, Silins I, et al: Nuclear expression of survivin is associated with improved survival in metastatic ovarian carcinoma. Cancer 109: 228-238, 2007.

37. Gong J, Chen N, Zhou Q, Yang B, Wang Y and Wang X: Melanoma inhibitor of apoptosis protein is expressed differentially in melanoma and melanocytic naevus, but similarly in primary and metastatic melanomas. J Clin Pathol 58: 1081-1085, 2005.

38. Crnkovic-Mertens I, Hoppe-Seyler F and Butz K: Induction of apoptosis in tumor cells by siRNA-mediated silencing of the livin/ML-IAP/KIAP gene. Oncogene 22: 8330-8336, 2003.

39. Crnkovic-Mertens I, Muley T, Meister M, et al: The anti-apoptotic livin gene is an important determinant for the apoptotic resistance of non-small cell lung cancer cells. Lung Cancer 54: 135-142, 2006.

40. Alvarez-Erviti L, Seow Y, Yin H, Betts C, Lakhal S and Wood MJ: Delivery of siRNA to the mouse brain by systemic injection of targeted exosomes. Nat Biotechnol 29: 341-345, 2011.

41. Feril LB Jr: Ultrasound-mediated gene transfection. Methods Mol Biol 542: 179-194, 2009. 